\title{
Safety and efficacy of transaxillary transcatheter aortic valve replacement using a current-generation balloon- expandable valve
}

Yong Zhan ${ }^{1 *}$ D, Nicholas Toomey ${ }^{1}$, Jamel Ortoleva ${ }^{2}$, Masashi Kawabori ${ }^{1}$, Andrew Weintraub ${ }^{3}$ and Frederick Y. Chen ${ }^{1}$

\begin{abstract}
Background: Transaxillary access (TAx) has shown promise as an excellent alternative TAVR option, but data on the Edwards SAPIEN 3 in TAx-TAVR is limited. We sought to study the safety and efficacy of TAx-TAVR using this current-generation balloon-expandable valve.

Methods: A retrospective study of our first 24 TAx and 20 transthoracic (TT) TAVR patients treated with the SAPIEN 3 valve was performed, and the patients' preoperative characteristics, procedural outcomes, and clinical outcomes were compared to our first 100 transfemoral (TF) patients using the SAPIEN 3 device.

Results: There were no statistical differences observed for outcomes between the TAx and TF groups, despite the TAx patients having more comorbidities (STS-PROM $11.3 \pm 7.6$ versus $7.3 \pm 5.2, p=0.042$ ). In addition, no significant difference was found in the fluoroscopy time and contrast amount between the two groups. The patients' baseline characteristics were similar between the TAx and $\Pi$ groups. Their procedural and clinical outcomes were comparable, but there was a trend towards lower incidence of acute kidney injury (13.0\% versus 23.5\%), new-onset atrial fibrillation (5.6\% versus 33.3\%), shorter median length of stay postoperatively (4 versus 6 days), fewer discharges to rehabilitation (16.7\% versus $35.0 \%$ ), and a lower rate of readmission within 30 -days (8.3\% versus 35.0\%), all favoring TAx access.

(Continued on next page)
\end{abstract}

\footnotetext{
* Correspondence: yzhan@tuftsmedicalcenter.org

${ }^{1}$ Division of Cardiac Surgery, CardioVascular Center, Tufts Medical Center, Tufts University School of Medicine, 800 Washington Street, \#266, Boston, MA 02111, USA

Full list of author information is available at the end of the article
}

(c) The Author(s). 2020 Open Access This article is licensed under a Creative Commons Attribution 4.0 International License, which permits use, sharing, adaptation, distribution and reproduction in any medium or format, as long as you give appropriate credit to the original author(s) and the source, provide a link to the Creative Commons licence, and indicate if changes were made. The images or other third party material in this article are included in the article's Creative Commons licence, unless indicated otherwise in a credit line to the material. If material is not included in the article's Creative Commons licence and your intended use is not permitted by statutory regulation or exceeds the permitted use, you will need to obtain permission directly from the copyright holder. To view a copy of this licence, visit http://creativecommons.org/licenses/by/4.0/ The Creative Commons Public Domain Dedication waiver (http://creativecommons.org/publicdomain/zero/1.0/) applies to the data made available in this article, unless otherwise stated in a credit line to the data. 
(Continued from previous page)

Conclusions: TAx-TAVR with the SAPIEN 3 valve is a safe alternative to TF access. It offers advantages of improved recovery over $\Pi$ access, and appears to be a superior alternative-access option for TAVR. TAx access could be preferred when TF access is not feasible.

Keywords: Transcatheter aortic valve replacement, Transaxillary, Alternative access, Balloon-expandable valve, SAPI EN 3

\section{Introduction}

Transcatheter aortic valve replacement (TAVR) has become a major therapy for patients with severe aortic valve stenosis, and the indications continue to evolve [1]. A variety of approaches must be considered when performing a TAVR procedure, including the method of vascular access as well as the type of device. While transfemoral access (TF) remains the default delivery route for TAVR, it is not always feasible. In such circumstances, alternative TAVR routes including transapical (TA), transaortic (TAo), and transaxillary (TAx) approaches have been utilized [2,3]; however, there is no consensus on the selection criteria for these approaches to TAVR.

TAx access is preferred over other non-transfemoral approaches in the setting of TAVR using self-expandable transcatheter valves [4]. There is growing evidence on the safety and efficacy of TAx-TAVR using balloonexpandable valves, but an individual operator's experience with the current-generation SAPIEN 3 valve (Edwards Lifesciences, Irvine, CA, USA) in TAx-TAVR is still limited [5]. In addition, much of the experience in TAx-TAVR was derived from studies focusing on left TAx access, which provides more coaxial orientation for device insertion, and therefore, is the predominant TAx approach [6,7]. We have developed a technique for right TAx-TAVR using the SAPIEN 3 valve to overcome the vascular tortuosity and unfavorable implantation angle inherent to this approach, and thus have expanded the patient population for the TAx approach [8].

While preferences for alternative TAVR approaches vary from institution to institution, tailoring TAVR to anatomic considerations and carefully choosing alternative access routes is critical to reduce vascular complications and facilitate recovery. As TAVR outcomes can be device and access-specific [9], we studied our institutional experience with the use of the SAPIEN 3 valve in various TAVR approaches, and sought to determine whether our current algorithm of alternative-access selection was effective.

\section{Materials and methods}

\section{Patient selection}

This is a single-center, retrospective, and comparative study of patients treated consecutively with the SAPI
EN 3 TAVR via alternative-access routes. In a total of 474 TAVR patients who underwent TAVR procedures between August 2015 and June 2019 at our institution, 24 had TAx-TAVR and 20 had transthoracic (TT-) TAVR, including TA and TAo approaches. They were compared to our first $100 \mathrm{TF}$ patients undergoing SAPIEN 3 TAVR during the study period.

The selection of an access route was at the discretion of our multi-disciplinary team, according to patient characteristic and anatomical considerations (Fig. 1). Patients who were not amenable to TFTAVR were screened for TAx access, which was considered over TT access (TAo or TA) at our institution. Left TAx access was favored, and right TAx access was chosen when the left axillary artery was $<5.5 \mathrm{~mm}$ or $<6.5 \mathrm{~mm}$ when there was a patent LIMA-dependent flow to the coronary artery. Vascular tortuosity was less of a concern, as it could be generally straightened by the rigid wire; however, calcification and small caliber could preclude TAx access. Selection of TAo versus TA access was determined based on patient characteristics and preoperative imaging data. TAo access was favored in patients with poor ventricular functions, underlying pulmonary issues, thinning or scarring of the apex of the heart, and close proximity of the aorta to the sternum, whereas TA access was preferred if the aorta was calcified or had patent bypass grafts, or the apex of the heart was adjacent to the intercostal space.

\section{Surgical technique}

The procedural technique for TAx-TAVR has been reported previously [10]. In brief, it is performed under general anesthesia via a surgical cut-down to expose the axillary artery for direct puncture (Fig. 2). When there are anatomical concerns, such as tortuosity, small caliber, or calcification of the subclavian artery, we place a V-18 $8^{\text {ma }}$ wire (Boston Scientific, Marlborough, MA, USA) via the ipsilateral brachial artery to the abdominal aorta to guide endovascular interventions as necessary (Fig. 2, arrow). We used the 'flip-n-flex' technique in right TAx-TAVR to facilitate coaxial alignment of the prosthesis and aortic annulus [8]. Primary repair of the axillary artery 


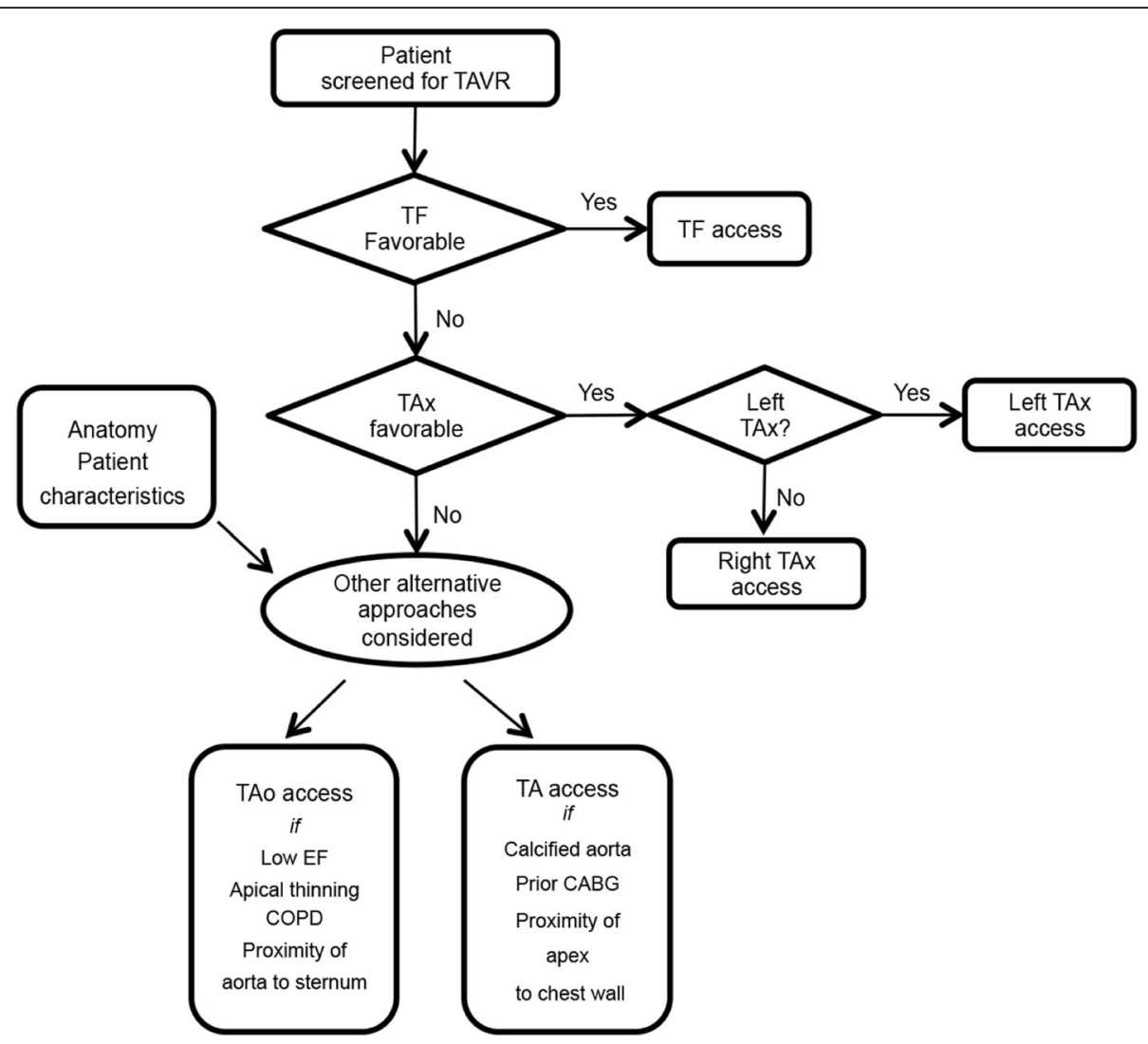

Fig. 1 Flowchart displays the algorithm of alternative access selection at our institution. TAVR, transcatheter aortic valve replacement; TF, transfemoral; TA, transapical; TAo, transaortic; TAx, transaxillary; EF, ejection fraction; COPD, chronic obstructive pulmonary disease

followed by angiography to confirm a successful repair was performed at the completion of the procedure.

Patients who were ineligible for the TAx approach were evaluated for either the TA or TAo approach. The TAo approach was performed via a small right thoracotomy in the 2nd intercostal space or a short J-shaped manubriotomy, based on the anatomical relationship of the ascending aorta to the sternum. The TA approach was performed via a thoracotomy through the intercostal space corresponding to the apex of the heart. The SAPIEN 3 device was inserted

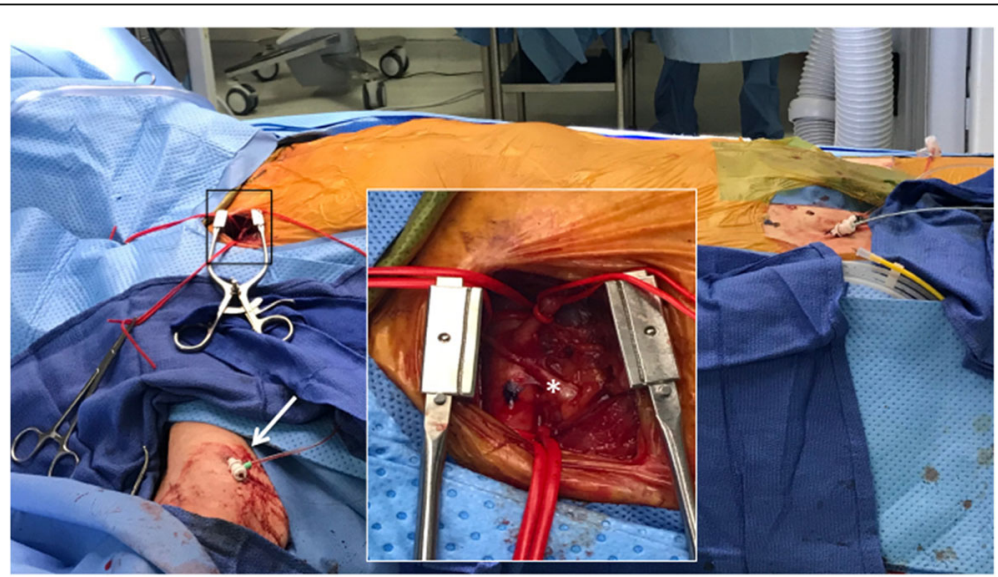

Fig. 2 Operative approach to transaxillary TAVR. The axillary artery is exposed via surgical cut-down, and the anatomy is shown in the inset. Note the brachial nerve $\left(^{*}\right)$ is in the vicinity of the axillary artery. Access to the brachial artery (arrow) is obtained in selected cases due to concerns for vascular complications 
through the Certitude sheath (Edwards LifeSciences, CA, USA). The technical aspects of the TA and TAo approaches for balloon-expandable valves have been previously described in the literature [11].

TF-TAVR was performed via percutaneous access, and closure of the femoral artery was performed using the ProGlide ${ }^{\bullet}$ Perclose device (Abbott Vascular, Santa Clara, CA, USA).

\section{Outcomes}

Study outcomes were 30-day mortality and complication rates, according to the Valve Academic Research Consortium (VARC)-2 definitions [12]. Fluoroscopy time, amount of contrast use, procedural time, postoperative length of stay, discharges to rehabilitation facilities, and readmissions were also studied.

\section{Statistical analysis}

Categorical data are presented as numbers and percentages, and continuous data as mean \pm standard deviation (SD) or as median and interquartile range (IQR). Comparisons among three groups were performed using Pearson $\chi^{2}$ test and Student's $t$ test or Kruskal-Wallis $\mathrm{H}$ test (non-parametric data). For comparisons between two groups, Pearson $X^{2}$ test or Fisher's exact test and Student's t test or Mann-Whitney U test (non-parametric data) were used, whenever appropriate. Results were considered as statistically significant when the $p$-value was less than 0.05 . Data analyses were performed using SPSS statistics software version 24 (IBM Corporation, Armonk, NY, USA).

\section{Results}

\section{Study cohort}

Among the 24 patients in the TAx group, 10 were treated with left TAx-TAVR and 14 right TAx-TAVR procedures. The TT group included $15 \mathrm{TA}$ and 5 TAo patients. Given the small numbers, the TA and TAo patients were grouped as one cohort for analysis. Literature suggests that these two TAVR approaches do not differ in major procedural and clinical outcomes $[13,14]$.

\section{Baseline characteristics}

The baseline characteristics of the three groups are summarized in Table 1. The STS-PROM scores of the TAx and TT groups were statistically higher than the TF group (11.3 \pm 7.6 and $11.9 \pm 11.8$ versus $7.3 \pm 5.2, p=$ 0.042 and $p=0.026$, respectively). Compared to the TF group, the TAx group had higher rates of diabetes (62.5\% versus $38 \%, p=0.029)$, chronic kidney disease (45.8\% versus $23 \%, p=0.024)$, chronic lung disease (58.3\% versus $23 \%, p=0.001)$, and history of percutaneous coronary intervention $(45.8 \%$ versus $19 \%, p=$ 0.006). The TT group was significant for the prevalence of end-stage renal disease ( $15 \%$ versus $2 \%$ for TF, $p=$ 0.032). The baseline characteristics between the TAx and TT groups were comparable, except for more patients with diabetes in the TAx group $(p=0.012)$. There were no significant differences among the preoperative echocardiographic data of the three groups. The TAx group had higher percentage of patients with pulmonary artery systolic pressure (PASP) $>40 \mathrm{mmHg}$, compared to the TF group ( $45.8 \%$ versus $14 \%, p=0.001$ ).

\section{Procedural outcomes}

The major procedural outcomes are summarized in Table 2. Device success rates were similar among the TF, TAx, and TT groups (96\% versus $95.8 \%$ versus $95 \%$, $p=0.683$ ). No significant differences were observed among the three groups with regard to bleeding events, vascular complications, cerebrovascular accidents, or permanent pacemaker implantation rates. Major vascular complications were rare; 2 TF patients had femoral artery stenosis due to the closure device, 1 TAx patient had focal dissection of the axillary artery required patch repair, and 1 TAo patient had femoral artery thrombosis. None of the patients in all three groups had coronary occlusion, whereas $4 \%$ of patients in the TF group and 1 out of $24(4.2 \%)$ in the TAx group underwent planned concurrent percutaneous coronary interventions. All patients had trace or mild paravalvular leak at the end of the procedure and follow-up at 30 days. There were no differences found among the TF, TAx, and TT groups in postprocedural transvalvular mean gradients $(10.2 \pm 4.4$ versus $8.7 \pm 3.2$ versus $9.2 \pm 3.6 \mathrm{mmHg}, p=0.187$ ).

As shown in Table 3, fluoroscopy time was shorter with the TT group $(12.4 \pm 5.0 \mathrm{~min})$ compared to the TF and TAx groups $(21.0 \pm 5.4 \mathrm{~min}$ and $23.9 \pm 9.3 \mathrm{~min}$, $p<0.001)$. Similarly, contrast amount was significantly less in the TT group $(126.0 \pm 45.4 \mathrm{ml})$ than the TF and TAx groups $(162.6 \pm 62.5 \mathrm{ml}$ and $155.4 \pm 44.9 \mathrm{ml}$, $p=0.039$ ). The overall procedural duration was shorter with the TF group $(112.0 \pm 28.3 \mathrm{~min}$ vs. $185.3 \pm 36.9 \mathrm{~min}$ for $\mathrm{TAx}$ and $156.5 \pm 35.6 \mathrm{~min}$ for TT; $\mathrm{p}<0.001$ and $p=0.004$, respectively).

\section{Clinical outcomes}

Clinical outcomes of the three groups are shown in Table 2. Statistical analyses were also performed between two groups (Fig. 3). The 30-day mortality rates of the three groups were not different $(1 \%$ versus $0 \%$ versus $5 \%$, TF versus TAx versus TT, $p=0.510$ ). Less than $10 \%$ of the patients in each group continued to have New York Heart Association (NYHA) class III or IV symptoms $(p=0.982)$.

The occurrences of new-onset atrial fibrillation $(5.6 \%$ versus $4.6 \%, p=0.869$ ), discharge to rehabilitation facility ( $16.7 \%$ versus $14 \%, p=0.750$ ), and 30 -day readmission 
Table 1 Patient Demographic and Preoperative Characteristics

\begin{tabular}{|c|c|c|c|c|c|}
\hline Variable & $\operatorname{TF}(n=100)$ & $\operatorname{TAx}(n=24)$ & $\mathrm{TT}(n=20)$ & $p$ Value & $\mathrm{p}$ Value between groups \\
\hline Age, years & $80.5 \pm 7.6$ & $82.9 \pm 8.8$ & $81.3 \pm 5.3$ & 0.386 & \\
\hline Male & $48(48)$ & $10(41.7)$ & $9(45)$ & 0.846 & \\
\hline Body mass index, $\mathrm{kg} / \mathrm{m}^{2}$ & $28.8 \pm 6.2$ & $27.1 \pm 6.2$ & $25.8 \pm 5.0$ & 0.095 & \\
\hline Body surface area, $\mathrm{m}^{2}$ & $1.9 \pm 0.2$ & $1.8 \pm 0.2$ & $1.8 \pm 0.3$ & 0.208 & \\
\hline Hypertension & $86(86)$ & $20(83.3)$ & $20(100)$ & 0.179 & \\
\hline Diabetes & $38(38)$ & $15(62.5)$ & $5(25)$ & 0.029 & $\begin{array}{l}\text { TF vs TAx, } 0.029 \\
\text { TAx vs TT, } 0.012\end{array}$ \\
\hline Coronary artery disease & $76(76)$ & $19(79.2)$ & $16(80)$ & 0.895 & \\
\hline Chronic kidney disease & $23(23)$ & $11(45.8)$ & $9(45)$ & 0.025 & $\begin{array}{l}\text { TF vs TAx, } 0.024 ; \\
\text { TF vs TT, } 0.042\end{array}$ \\
\hline End-stage renal disease & $2(2)$ & $1(4.2)$ & $3(15)$ & 0.029 & TF vs TT, 0.032 \\
\hline Creatinine ${ }^{a}, \mathrm{mg} / \mathrm{dL}$ & $1.3 \pm 1.1$ & $1.6 \pm 0.9$ & $1.6 \pm 1.6$ & 0.291 & \\
\hline Chronic lung disease & $23(23)$ & $14(58.3)$ & $8(40)$ & 0.002 & TF vs TAx, 0.001 \\
\hline Cerebrovascular accident & $11(11)$ & $5(20.8)$ & $5(25)$ & 0.171 & \\
\hline Previous cardiac surgery & $17(17)$ & $5(20.8)$ & $7(35)$ & 0.186 & \\
\hline Previous CABG & $16(16)$ & $4(16.7)$ & $7(35)$ & 0.133 & \\
\hline Previous PCl & $19(19)$ & $11(45.8)$ & $7(35)$ & 0.015 & TF vs TAx, 0.006 \\
\hline Permanent pacemaker & $11(11)$ & $0(0)$ & $0(0)$ & 0.073 & \\
\hline Atrial fibrillation & $35(35)$ & $6(25.0)$ & $5(25)$ & 0.495 & \\
\hline NYHA III/IV & $90(90)$ & $22(91.7)$ & $18(90)$ & 0.969 & \\
\hline STS-PROM & $7.3 \pm 5.2$ & $11.3 \pm 7.6$ & $11.9 \pm 11.8$ & 0.005 & $\begin{array}{l}\text { TF vs TAx, } 0.042 ; \\
\text { TF vs TT, } 0.026\end{array}$ \\
\hline \multicolumn{6}{|l|}{ Echocardiographic data } \\
\hline Aortic valve area, $\mathrm{cm}^{2}$ & $0.7 \pm 0.2$ & $0.8 \pm 0.1$ & $0.7 \pm 0.2$ & 0.354 & \\
\hline Peak gradient, mmHg & $68.9 \pm 23.4$ & $60.6 \pm 19.4$ & $66.7 \pm 20.4$ & 0.259 & \\
\hline Mean gradient, mmHg & $39.2 \pm 13.9$ & $35.5 \pm 11.6$ & $39.7 \pm 14.0$ & 0.378 & \\
\hline Peak velocity, m/s & $4.1 \pm 0.7$ & $3.8 \pm 0.6$ & $4.0 \pm 0.7$ & 0.229 & \\
\hline LVEF, \% & $54.8 \pm 11.6$ & $53.0 \pm 11.1$ & $49.0 \pm 15.4$ & 0.142 & \\
\hline $\mathrm{PASP}>40 \mathrm{mmHg}$ & $14(14)$ & $11(45.8)$ & $6(30)$ & 0.002 & TF vs TAx, 0.001 \\
\hline
\end{tabular}

${ }^{a}$ Creatinine level is the most recent value before surgery

Values are mean $\pm \mathrm{SD}$ or $\mathrm{n}(\%)$

CABG coronary artery bypass graft, $P C I$ percutaneous coronary intervention, LVEF left ventricular ejection fraction, NYHA New York Heart Association classification, PASP pulmonary artery systolic pressure, STS-PROM Society of Thoracic Surgeons predicted risk of mortality score, TAx transaxillary, TF transfemoral,

$\pi$ transthoracic

(8.3\% versus $8 \%, p=0.957)$ were comparable between the TF and TAx groups. The TAx group had numerically, but not statistically, higher rate of acute kidney injury (AKI) in comparison to the TF group (13.0\% versus $5.1 \%, p=0.175)$. Between the TAx and TT groups, there was a trend towards a lower incidence of newonset atrial fibrillation, fewer discharges to rehabilitation facilities, and a lower readmission rate within 30days, favoring the TAx group, although the differences did not reach statistical significance (Fig. 3). Compared to the TF group, the TT group was associated with a higher incidence of AKI (23.5\% versus 5.1\%, $p=$ $0.026)$, new-onset atrial fibrillation (33.3\% versus $4.6 \%$, $p=0.005)$, discharge to rehabilitation facility ( $35 \%$ vs. $14 \%$, $p=0.047$ ), and 30-day readmission (35\% versus $8 \%, p=$ 0.004) (Fig. 3).

The TAx and TT groups both had longer postprocedural hospital length of stay (LOS) than the TF group $(p<0.001)$. Although non-significant, the TAx group had a shorter median LOS than the TT group (4 versus 6 days, $p=0.132$ ).

\section{Discussion}

TAVR devices have improved dramatically over time, which allows the vast majority of device deliveries through femoral arteries. However, there are still patients with peripheral vascular disease who are not candidates for TF-TAVR. In our study period of the SAPI 
Table 2 Procedural and Clinical Outcomes

\begin{tabular}{|c|c|c|c|c|}
\hline Variable & $\operatorname{TF}(n=100)$ & $\operatorname{TAx}(n=24)$ & $T T(n=20)$ & p Value \\
\hline \multicolumn{5}{|l|}{ VARC- 2 outcomes } \\
\hline Device success & $98(98)$ & $23(95.8)$ & $19(95)$ & 0.683 \\
\hline Bleeding & $5(5)$ & $1(4.2)$ & $0(0)$ & 0.593 \\
\hline Life-threatening bleeding & $0(0)$ & $0(0)$ & $0(0)$ & $\ldots$ \\
\hline Major bleeding & $3(3)$ & $0(0)$ & $0(0)$ & 0.510 \\
\hline Minor bleeding & $2(2)$ & $1(4.2)$ & $0(0)$ & 0.625 \\
\hline Vascular complication & $6(6)$ & $1(4.2)$ & $1(5)$ & 0.933 \\
\hline Major & $3(3)$ & $1(4.2)$ & $1(5)$ & 0.887 \\
\hline Minor & $3(3)$ & $0(0)$ & $0(0)$ & 0.510 \\
\hline Cerebrovascular accident & $2(2)$ & $0(0)$ & $1(5)$ & 0.510 \\
\hline Coronary artery obstruction & $0(0)$ & $0(0)$ & $0(0)$ & $\ldots$ \\
\hline Pacemaker insertion ${ }^{a}$ & 8/89 (8.9) & $4(16.7)$ & $5(25)$ & 0.125 \\
\hline Paravalvular leak (<moderate) & $100(100)$ & $24(100)$ & $20(100)$ & 1.000 \\
\hline Acute kidney injury ${ }^{b}$ & $5 / 98(5.1)$ & $3 / 23(13.0)$ & 4/17 (23.5) & 0.032 \\
\hline Stage 1 & $3(3)$ & $2(8.3)$ & $3(15)$ & 0.048 \\
\hline Stage 2 & $2(2)$ & $1(4.2)$ & $1(5)$ & 0.617 \\
\hline 30-day Mortality & $2(2)$ & $0(0)$ & $1(5)$ & 0.510 \\
\hline \multicolumn{5}{|l|}{ Other outcomes } \\
\hline Transfusion & $5(5)$ & $0(0)$ & $2(10)$ & 0.305 \\
\hline New-onset atrial fibrillation ${ }^{c}$ & 3/65 (4.6) & 1/18 (5.6) & 5/15 (33.3) & 0.002 \\
\hline Postoperative NYHA III/IV & $9(9)$ & $2(8.3)$ & $2(10)$ & 0.982 \\
\hline Mean gradient, mmHg & $10.2 \pm 4.4$ & $8.7 \pm 3.2$ & $9.2 \pm 3.6$ & 0.187 \\
\hline Discharge to rehabilitation & $14(14)$ & $4(16.7)$ & $7(35)$ & 0.077 \\
\hline 30-day readmission & $8(8)$ & $2(8.3)$ & $7(35)$ & 0.002 \\
\hline
\end{tabular}

Patients with permanent pacemaker ${ }^{\mathrm{a}}$, end-stage renal disease ${ }^{\mathrm{b}}$, or atrial fibrillation ${ }^{\mathrm{c}}$ at baseline are excluded Values are mean \pm SD or $\mathrm{n}(\%)$

NYHA New York Heart Association classification, PPM permanent pacemaker, TAx transaxillary, TF transfemoral, $T$ transthoracic, VARC Valve Academic

Research Consortium

EN 3 platform, alternative-access TAVRs comprised approximately $10 \%$ of our total TAVR volume. With the results of recent clinical trials leading to the approval of TAVR in patients at lower surgical risks, the indications for TAVR continue to expand $[15,16]$. This further lowered the risk-profile of patient cohorts, in particular, the patients undergoing TF-TAVR. Therefore, we selected our first 100 TF-TAVR patients for a better comparison with the alternative-access patients who tended to have higher STS-PROM scores. In addition, this study represents our initial experience with the SAPIEN 3 valve in the individual access route available at our institution.

While the left TAx approach with the SAPIEN 3 valve has become our alternative-access of choice, certain patients have anatomical or pathological features of the left subclavian artery that make this approach undesired. In such circumstances, the right axillary artery is considered as the next step in our practice. The overall outcomes of our TAx and TF

Table 3 Comparison of TAVR Approaches on Procedural and Clinical Efficiency

\begin{tabular}{llllllll}
\hline Variables & TF $(\mathbf{n}=\mathbf{1 0 0})$ & TAx $(\mathbf{n}=\mathbf{2 4})$ & $\mathbf{T T}(\mathbf{n}=\mathbf{2 0})$ & $\mathbf{p}$ value & TF vs. TAx & TAx vs. TT & TF vs. TT \\
\hline Fluoroscopy time, min & $21.0 \pm 5.4$ & $23.9 \pm 9.3$ & $12.4 \pm 5.0$ & $<0.001$ & 0.105 & $<0.001$ & $<0.001$ \\
Contrast amount, $\mathrm{mL}$ & $162.6 \pm 62.5$ & $155.4 \pm 44.9$ & $126.0 \pm 45.4$ & 0.039 & 0.850 & 0.217 & 0.029 \\
Procedural time, min & $112.0 \pm 28.3$ & $185.3 \pm 36.9$ & $156.5 \pm 35.6$ & $<0.001$ & $<0.001$ & 0.047 & 0.004 \\
Post-procedural LOS, d & $3(2-4)$ & $4(3-6)$ & $6(4-7)$ & $<0.001$ & $<0.001$ & 0.132 & $<0.001$ \\
\hline
\end{tabular}

Values are mean \pm SD or median (interquartile range) 


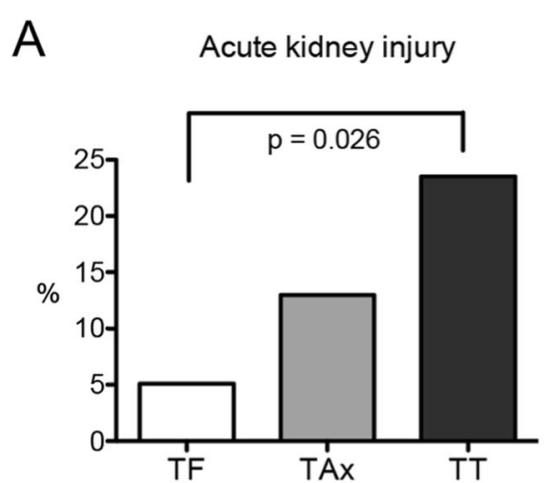

C

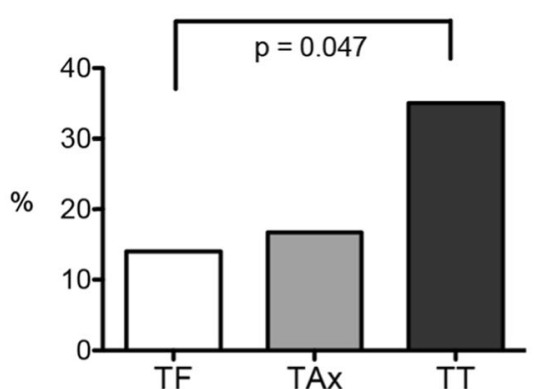

B

New-onset atrial fibrillation

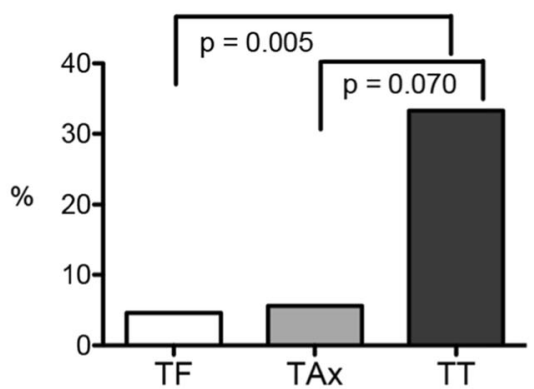

D

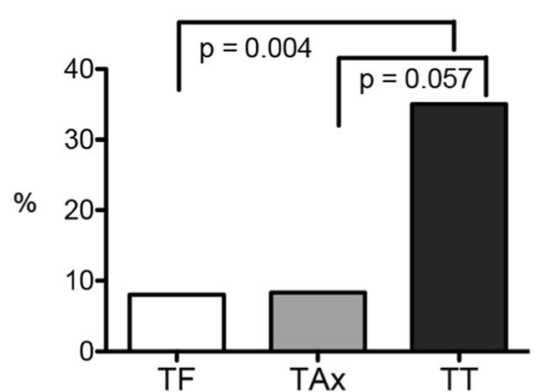

Fig. 3 Comparison of postoperative outcomes between TAVR approaches. a Acute kidney injury. b New-onset atrial fibrillation. c Discharge to rehabilitation. d 30-day readmission. TF, transfemoral; TAx, transaxillary; TT, transthoracic

cohorts were comparable, despite that higher incidences of comorbidities were seen with the TAx cohort. This supports the notion that the TAx approach continues to be a preferred alternative-access option in the current era of newer-generation devices. Previous studies comparing the procedural and clinical outcomes of the TAx and TF approaches demonstrated that TAx-TAVR is associated with overall similar outcomes to TF-TAVR using self-expandable valves [4].

Patients who underwent alternative-access TAVR were associated with higher risk-profile. However, equivalent technical success could be achieved with all approaches. In comparison to the TF group, the TT but not TAx group had a significantly higher incidence of new-onset atrial fibrillation. Our result not only is in agreement with the finding of a previous report in which the TA and TAo approaches are associated with increased risk for new-onset atrial fibrillation [5], but also serves as evidence that TAx-TAVR does not differ from TF-TAVR in regard to major outcomes. The higher risk-profiles did not necessarily translate into higher postoperative complications for the TAx patients. We observed that more patients in the TAx and TT groups had AKI after the TAVR procedure. This finding did not correlate with contrast amount or duration of the procedure. Reduction in contrast amount could be off-set by the higher prevalence of chronic kidney disease in the two groups at baseline, which may rationalize the AKI rate of the TAx group, but does not appear to account for that of the TT group. In the literature, higher incidences of AKI have been reported for TA- or TAo-TAVR than TAx-TAVR $[17,18]$.

The alternative-access of choice for TAVR remains to be elucidated $[2,3]$. We achieved comparable procedural outcomes with different TAVR approaches, but the patients who underwent the TT approach required more complex patient care postoperatively, as evidenced by longer LOS and higher rates of readmission and discharge to rehabilitation facility (Fig. 3). Studies revealed that TA- or TAo-TAVR could be associated with higher mortality and decreased survival $[5,17,19]$. Our liberal use of the left and right TAx approaches allowed us to avoid thoracic access in the majority of cases (24/44, $54.5 \%)$ where alternative-access routes were deemed necessary. However, when the right TAx approach is also precluded, selection of next available alternative access becomes critical. Transcaval and transcarotid access routes have been explored and shown promising results $[20,21]$. More evidence suggests that patients that underwent these peripheral TAVR approaches can 
benefit from the reduced invasiveness, although procedural and clinical effectiveness require further evaluation [22]. A study comparing the transcarotid and TAx approaches revealed comparable outcomes [23]. Data on the efficacy and safety of either of these approaches is scant, and there were no randomized control studies comparing alternative TAVR approaches to date. Choosing an alternative TAVR route is based on its availability at an individual institution, and depends on a surgical team's proficiency in performing the procedure.

The current study cohort represents our initial experience with the TAx approach, whereas TA and TAo had been performed with previous-generation balloonexpandable valves. Low-profile delivery systems facilitate the conduct of the procedure. An improvement in the fluoroscopy time in right TAx-TAVR owing to the 'flip$\mathrm{n}$-flex' technique was described in our previous report [10]. As a result, the fluoroscopy time of the entire TAx cohort was similar to the TF cohort. On the other hand, the shorter procedural time of the TT cohort relates to the relatively straightforward insertion of the delivery system and our pre-existing experience with the TA and TAo approaches. Each approach has unique features, and technical challenges could be anticipated in individual access. Familiarity with axillary access facilitates our adoption of the TAx approach, as the axillary artery is used routinely as an alternative cannulation site. We currently perform TAx-TAVR via surgical cut-down. It has been reported that TAx-TAVR can be performed percutaneously, albeit covered stent placement is required in more than $10 \%$ of cases [24]. In contrast, the open technique carries a lower risk of bleeding or vascular complications, but potentially at the cost of longer recovery.

Vascular complications remain a concern in the current era despite continuous improvement in the delivery devices. This calls for a broader use of alternative-access and strengthens the notion that TAVR access should be carefully selected to ensure procedural safety. Our experience demonstrates that TAx access is safe and effective using the current-generation TAVR device. A judicious selection of the laterality for TAx-TAVR potentially reduces adverse vascular events and expands the use of this less-invasive TAVR approach. With accumulated experience, alternative TAVR approaches such as TA or TAo can also be safely and effectively performed. However, the TAx approach offers advantages over the TT approach with improved patient recovery, and it could be considered when femoral access is not available.

\section{Study limitations}

We report single-center experience of alternative-access TAVR using the SAPIEN 3 device. Due to limited sample sizes, comparisons among the groups could be underpowered, and therefore, some of the results were suggestive but not conclusive. These groups also differ in some baseline features, and the small patient numbers limited our ability to perform propensity-score matching. Future large studies could help to elucidate this matter. Due to our early experience, long-term outcomes of the study cohorts were lacking.

\section{Conclusion}

TAx access for TAVR with the SAPIEN3 valve is a safe alternative to TF-TAVR. Despite the patients undergoing TAx-TAVR procedures with higher risk profiles, we have shown that excellent procedural and short-term clinical outcomes can be achieved using our current approach to access route selection. TAx access offers advantages of improved recovery over TT access, and appears to be a superior alternative-access option for TAVR. It could be preferred when TF access is not feasible.

\section{Abbreviations \\ AKI: Acute kidney injury; LOS: Length of stay; STS-PROM: Society of Thoracic Surgeons predicted risk of mortality; TA: Transapical; TAo: Transaortic; TAVR: Transcatheter aortic valve replacement; TAx: Transaxillary; TF: Transfemoral; TT: Transthoracic; VARC: Valve Academic Research Consortium}

\section{Acknowledgements}

Not applicable.

\section{Authors' contributions}

YZ conceptualized the study, investigated and validated the data, and wrote the original draft of the manuscript. NT and JO investigated and analyzed the data. MK and AW validated the study methodology and critically reviewed the manuscript. FC provided supervision. All authors read and approved the final manuscript.

\section{Funding}

None.

\section{Availability of data and materials}

Supporting data are available through the corresponding author on reasonable request.

\section{Ethics approval and consent to participate}

The Institutional Review Board at Tufts Medical Center approved this study.

\section{Consent for publication}

The need for patient consent was waived.

\section{Competing interests}

The authors have no competing interests to declare.

\section{Author details}

${ }^{1}$ Division of Cardiac Surgery, CardioVascular Center, Tufts Medical Center, Tufts University School of Medicine, 800 Washington Street, \#266, Boston, MA 02111, USA. ²Division of Cardiac Anesthesia, Tufts Medical Center, Tufts University School of Medicine, Boston, MA, USA. ${ }^{3}$ Division of Cardiology, CardioVascular Center, Tufts Medical Center, Tufts University School of Medicine, Boston, MA, USA. 
Received: 22 May 2020 Accepted: 3 September 2020

Published online: 10 September 2020

\section{References}

1. Freemantle N, Irs A, De Paulis R, Pagano D, Falk V, Beyersdorf F. Transcatheter versus surgical aortic valve replacement: what does the latest evidence tell us? Eur J Cardiothorac Surg. 2019;56:7-9.

2. Lanz J, Greenbaum A, Pilgrim T, Tarantini G, Windecker S. Current state of alternative access for transcatheter aortic valve implantation. Eurolntervention. 2018;14:AB40-52.

3. Overtchouk P, Modine T. Alternate access for TAVI: stay clear of the chest. Interv Cardiol. 2018;13:145-50.

4. Gleason TG, Schindler JT, Hagberg RC, et al. Subclavian/axillary access for self-expanding transcatheter aortic valve replacement renders equivalent outcomes as transfemoral. Ann Thorac Surg. 2018;105:477-83.

5. Dahle TG, Kaneko T, McCabe JM. Outcomes following subclavian and axillary artery access for transcatheter aortic valve replacement: Society of the Thoracic Surgeons/American College of Cardiology TVT registry report. JACC Cardiovasc Interv. 2019;12:662-9.

6. van der Wulp K, Verkroost MWA, van Wely MH, et al. Feasibility and outcomes of transcatheter aortic valve implantation using the left axillary artery as primary access site. Ann Thorac Surg. 2019;107:546-52.

7. Caceres M, Braud R, Roselli EE. The axillary/subclavian artery access route for transcatheter aortic valve replacement: a systematic review of the literature. Ann Thorac Surg. 2012;93:1013-8.

8. Zhan Y, Kawabori M, Lofftus S, Weintraub A. Simple "flip-n-flex" technique facilitates coaxial SAPIEN 3 valve alignment in right transaxillary transcatheter aortic valve replacement. Eurolntervention. 2019;15:e340-1.

9. Abdel-wahab M, Mehilli J, Frerker C, et al. Comparison of balloonexpandable vs self-expandable valves in patients undergoing transcatheter aortic valve replacement: the CHOICE randomized clinical trial. JAMA. 2014; 311:1503-14.

10. Zhan Y, Kawabori M, Lofftus S, et al. Right transaxillary transcatheter aortic valve replacement using the "Flip-n-flex" technique. Ann Thorac Surg. 2020; 109:57-62.

11. George I, Kriegel J, Nazif T, et al. Transthoracic access for transcatheter aortic valve replacement: technique using the Edwards Sapien retroflex delivery system. Ann Thorac Surg. 2014;98:347-9.

12. Kappetein AP, Head SJ, Généreux P, et al. Updated standardized endpoint definitions for transcatheter aortic valve implantation: the valve academic research Consortium-2 consensus document. Eur J Cardiothorac Surg. 2012; 42:545-60.

13. Thourani VH, Jensen HA, Babaliaros V, et al. Transapical and transaortic transcatheter aortic valve replacement in the United States. Ann Thorac Surg. 2015;100:1718-26.

14. O'Sullivan KE, Hurley ET, Segurado R, Sugrue D, Hurley JP. Transaortic TAVI is a valid alternative to transapical approach. J Card Surg. 2015;30:381-90.

15. Mack MJ, Leon MB, Thourani VH, et al. Transcatheter aortic-valve replacement with a balloon-expandable valve in low-risk patients. N Engl J Med. 2019;380:1695-705.

16. Popma JJ, Deeb GM, Yakubov SJ, et al. Transcatheter aortic-valve replacement with a self-expanding valve in low-risk patients. N Engl J Med. 2019;380:1706-15.

17. Taramasso M, Maisano F, Cioni M, et al. Trans-apical and trans-axillary percutaneous aortic valve implantation as alternatives to the femoral route: short- and middle-term results. Eur J Cardiothorac Surg. 2011;40:49-55.

18. Reardon MJ, Adams DH, Coselli JS, et al. Self-expanding transcatheter aortic valve replacement using alternative access sites in symptomatic patients with severe aortic stenosis deemed extreme risk of surgery. J Thorac Cardiovasc Surg. 2014;148:2869-76.

19. Arai T, Romano M, Lefèvre $T$, et al. Direct comparison of feasibility and safety of transfemoral versus transaortic versus transapical transcatheter aortic valve replacement. JACC Cardiovasc Interv. 2016;9:2320-5.

20. Folliguet $T A$, Teiger $E$, Beurtheret $\mathrm{S}$, et al. Carotid versus femoral access for transcatheter aortic valve implantation: a propensity score inverse probability weighting study. Eur J Cardiothorac Surg. 2019:56:1140-6.

21. Paone G, Eng M, Kabbani LS, et al. Transcatheter aortic valve replacement: comparing transfemoral, transcarotid, and transcaval access. Ann Thorac Surg. 2018;106:1105-12.
22. Beve M, Auffret $V$, Belhaj Soulami $R$, et al. Comparison of the transarterial and transthoracic approaches in nontransfemoral transcatheter aortic valve implantation. Am J Cardiol. 2019;123:1501-9.

23. Amer MR, Mosleh W, Joshi S, et al. Comparative outcomes of transcarotid and transsubclavian transcatheter aortic valve replacement. Ann Thorac Surg. 2020;109:49-56.

24. Schäfer U, Deuschl F, Schofer N, et al. Safety and efficacy of the percutaneous transaxillary access for transcatheter aortic valve implantation using various transcatheter heart valves in 100 consecutive patients. Int J Cardiol. 2017;232:247-54.

\section{Publisher's Note}

Springer Nature remains neutral with regard to jurisdictional claims in published maps and institutional affiliations.
Ready to submit your research? Choose BMC and benefit from:

- fast, convenient online submission

- thorough peer review by experienced researchers in your field

- rapid publication on acceptance

- support for research data, including large and complex data types

- gold Open Access which fosters wider collaboration and increased citations

- maximum visibility for your research: over $100 \mathrm{M}$ website views per year

At BMC, research is always in progress.

Learn more biomedcentral.com/submissions 